\title{
The Study on Whole Body Vibration Exposure Induces Low Back Pain among Uthm Bus Drivers
}

\author{
AHMAD FUAD Mohd Noor, a , MUSLI Nizam Yahya, ${ }^{1, b}$ \\ MOHD IMRAN Ghazali ${ }^{1, c}$, NOR AZALI Azmir ${ }^{1, d}$, \\ HARI KRISHNAN Tamil Selvan ${ }^{2, e}$ \\ ${ }^{1}$ Department of Mechanic, Faculty of Mechanical and Manufacturing Engineering, Universiti Tun \\ Hussein Onn Malaysia (UTHM) 86400 Parit Raja, Batu Pahat Johor, Malaysia \\ 2 Ergonomics Excellence Centre, Southern Regional Office (Johor Bahru), No 10 Jalan Persiaran \\ Teknologi, Taman Teknologi Johor, 81400 Senai Johor, Malaysia \\ aadmnoor91@gmail.com, bmusli@uthm.edu.my, ${ }^{\mathrm{c} i m r a n @ u t h m . e d u . m y, ~}{ }^{\mathrm{d}}$ azali@uthm.edu.my, \\ ehari.krishnan@niosh.com.my
}

Keywords: Whole body vibration, low back pain, bus drivers, vibration exposure level

\begin{abstract}
Buses are one of the important public transportation in Malaysia and commonly important for the student in any university. Thus, the study about Whole-Body Vibration (WBV) exposure induces to Low Back Pain (LBP) among the Universiti Tun Hussein Onn Malaysia (UTHM) was done. The objective was determine whether the bus drivers in UTHM would exceed the exposure action and limit values from the ISO 2631-1 (1997) during the working hours. Data collected according to different type of buses and evaluated the vibration significant different between buses based on the subjective correlation due to WBV questionnaire analysis. Analyze the prevalence of LBP based on the measurement and the questionnaire analysis. The study based on the international standard ISO 2631-1 (1997) which is related to the root-men-square (r.m.s) and Vibration Dose Value (VDV) parameter. The study covered among the bus drivers in UTHM. The measurement tools involved in the study is Larson Davis Vibration Meter (HVM 100) with Triaxial Seat Pad Accelerometer to record data collection. The BLAZE software analyze the vibration exposure exceed the total vibration exposure according to 8 hours day $\mathrm{A}(8)$ value of $1.15 \mathrm{~m} / \mathrm{s}^{2}$ and VDV value of $21.0 \mathrm{~m} / \mathrm{s}^{1.75}$. The IBM Statistical Package for Social Science (SPSS) was used to do statistical analysis and testing involved was correlation, regression and ANOVA. Result obtained shows the $A(8)$ and VDV was under EAV with highest value of $0.520 \mathrm{~m} / \mathrm{s}^{2}$ and $12.65 \mathrm{~m} / \mathrm{s}^{1.75}$. The highest contribution factors by the duration to complete single trip per day expose to WBV. The further re-assess of working schedule need to be done in order to control the exposure level toward drivers. The assessment should be done for every two years.
\end{abstract}

\section{Introduction}

This type of bus is really important as a main transportation for the student of Universiti Tun Hussein Onn Malaysia (UTHM). The reason because occupational drivers such as bus drivers are one group of workers that have been reported widely as being at increased risk for LBP [1]. An adverse affects over a lifetime of exposure based on average 8-hours daily equipment exposure [2]. The bus driver in UTHM was determine whether would exceed the exposure action and limit values from the ISO 2631-1 (1997). During exposure to WBV there are many physiological, psychological and physical factors which are relevant for the development of unwanted effects [3]. Many researchers have concluded that exposure to WBV, postural stress from awkward and sedentary position may contribute to an increased risk of low back pain [4].

The most frequently cited and research-supported problem/injury is lower back pain [5]. Indeed, LBP has been reported to be main cause of sick leave in developing world [1]. WBV involves the transmission of mechanical vibration to the entire human body while in any of the three postures of standing, sitting, or reclining, with frequencies of concern ranging from 0.5 to $80 \mathrm{~Hz}$ [6]. Accordingly, measurement of WBV should be conducted on the surface transmitting vibration to 
the human body [3]. There are also safety concerns associated with WBV, vibration frequencies which match the resonant frequency of the body have been shown to hamper a worker's ability to perform job tasks [7].

The study need to be conducted in proper and systematic way to achieve good result. The focus of the study determined whether the UTHM bus drivers would exceed the exposure action and limit values from the ISO 2631-1 (1997) during their typical working hours according to different type of buses. The data collection was evaluate due to vibration significant different between type of buses based on the subjective correlation due to WBV questionnaire and the prevalence of LBP analyzed according to data measurement and questionnaire analysis.

\section{Methodology}

The subject for this study was UTHM bus driver with average daily working 5 to 8 hours. The type of buses can be referring to the Table 1 . About 36 drivers were selected into the study. The subject must be good in health and were interviewed using the modified WBV questionnaire in Malay version adapted from the standardised Nordic questionnaires for the analysis of musculoskeletal symptoms [8]. The question was divided into five categories which was personal identification, working information, bus condition, worker health, and back pain problem.

Table 1: The type of buses

\begin{tabular}{ccc}
\hline \multicolumn{3}{c}{ Type of buses } \\
\hline Manufacturer & Model & Year \\
\hline HINO & RK1JSKA & 2001 \\
HINO & RM1ESKU & 2012 \\
NISSAN & JA450S & 2009 \\
HINO & AK1JRKA & 2003 \\
NISSAN & JP251S & 2003 \\
NISSAN & JP251P & 2002 \\
\hline
\end{tabular}

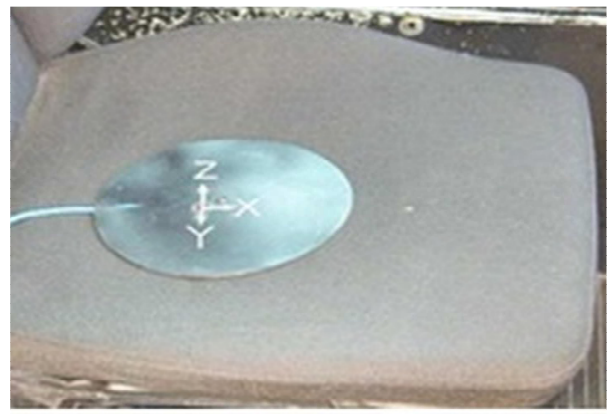

Figure 1: The position of Seat Pad Accelerometer

The measurement tools of Tri-Axial seat pad accelerometer and Spectral human vibration meter analyzer (HVM 100) was used. The weighting-frequency according to basicentric of human body for the bus driver must correct for $\mathrm{A}(8)$ and VDV data collection. The value for both weightingfrequencies was $\left(\mathrm{W}_{\mathrm{d}}=1.4 \mathrm{a}_{\mathrm{wx}}, \mathrm{W}_{\mathrm{d}}=1.4 \mathrm{a}_{\mathrm{wy}}\right.$ or $\left.\mathrm{W}_{\mathrm{k}}=1.0 \mathrm{a}_{\mathrm{wz}}\right)$. The position of the seat-pad accelerometer placed on the driver seat according to basicentric position of seated person as shown in Fig. 1. The data collected was four minutes recorded. This was due to the limitation and technical issues on the HVM 100 during the study.

The data from the HVM 100 was analyzed by using BLAZE software to run analysis of A(8) and VDV parameter. The Exposure Action Value (EAV) and Exposure Limit Value for A(8) and VDV according to EU Directive as below;
- $\quad \mathrm{EAV} / \mathrm{A}(8)=0.50 \mathrm{~m} / \mathrm{s}^{2}$
- $\mathrm{ELV} / \mathrm{A}(8)=1.15 \mathrm{~m} / \mathrm{s}^{2}$
- $\quad \mathrm{EAV} / \mathrm{VDV}=9.1 \mathrm{~m} / \mathrm{s}^{1.75}$
- $\mathrm{ELV} / \mathrm{VDV}=21.0 \mathrm{~m} / \mathrm{s}^{1.75}$

Different level of EAV/ELV indicated different rating of risk exposure by the bus drivers. The value of $A(8)$ and VDV can be calculated using several formula. The value of r.m.s or known as $A_{w}$ extrapolated to an 8 -hour daily value, unit of $\mathrm{m} / \mathrm{s}^{2}$ should be obtained by using Equation (1).

$$
A_{W}=\left[\frac{1}{T} \int_{0}^{T} a_{W}^{2}(t) d t\right]^{\frac{1}{2}}
$$

where; $T$ was the time observation which was four minutes and $t$ was indicated the time the subject exposure to vibration. The formula of VDV for daily exposure should be obtained by using Equation (2),

$$
V D V=\left[\int_{0}^{T} a_{W}^{4}(t) d t\right]^{\frac{1}{4}}
$$


where, $T$ was the duration of measurement was four minutes and $\mathrm{a}_{\mathrm{w}}(t)$ was the instantaneous frequency-weighted acceleration. All the formula was referred to the ISO 2631-1 (1997) and value of A(8) and VDV from four minutes data collection to an 8-hour daily value was used HSE calculator calculated those values. The data from measurement was analyzed by using Blaze software. The statistical analysis by SPSS was done for determined the relationship between WBV to the LBP problem after running the test of correlation, regression and ANOVA. The testing of correlation was the relationship between two variables or concept numerically. Thus, the variables formed a hypothesis known as null hypothesis. The $p$-value and $\alpha$-value for indicated the strength of correlation. The strength of $\alpha$-value was by the significant value of correlation as below.

- $\alpha$-value (moderate-weak) $<0.5$

- $\alpha$-value (strong-very strong) $\geq 0.6$

The regression testing was statistical tool investigate relationship between independent and dependent variables. The value of significant level according to SPSS is $\alpha$-value $=0.500$. The decision making for regression testing to the null hypothesis was as below.

- $\quad$ Sig-F $<\alpha$-value $=$ rejected

- $\quad$ Sig-F $\geq \alpha$-value $=$ accepted

The ANOVA testing used to different the mean score of the dataset. ANOVA capable to analyze and do compares two, three, and five, of $\mathrm{n}$ value of mean score. The significant level for ANOVA same as regression significant level. The detail on study methodology illustrated as schematics of WBV data collection process according to Fig. 2.

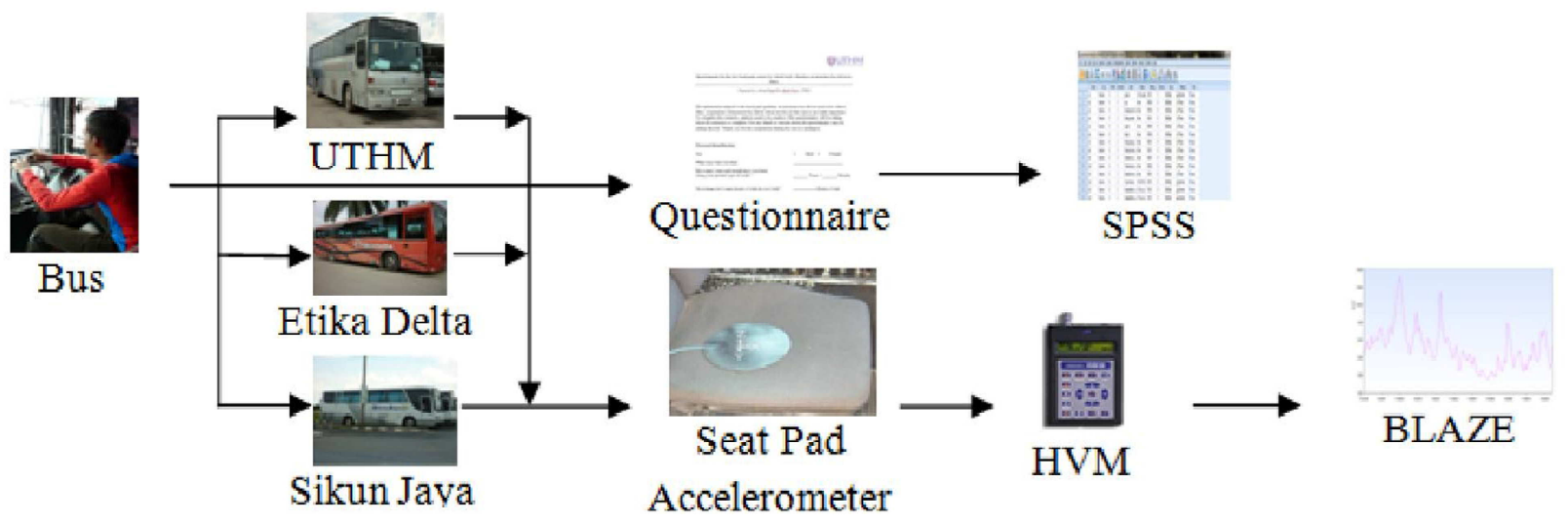

Figure 2: The Schematics WBV Data Collection System

\section{Result and discussion}

The result obtained from the BLAZE software for the $A(8)$ according to the Fig. 3 . According to the Fig. 3, all the model of buses was under ELV. For the model NISSAN JP251P with $\mathrm{A}(8)=0.52$ $\mathrm{m} / \mathrm{s}^{2}$ was the highest by reached EAV. There was HINO RM1ESKU and HINO AK1JRKA $(0.465$ $\mathrm{m} / \mathrm{s}^{2}$ and $0.435 \mathrm{~m} / \mathrm{s}^{2}$ ) approached to EAV. Surveillance action and precaution must do. Model of NISSAN JP251P need undergoes serious action and control in order to avoid exceeded ELV. The action such as do the assessment on required vibration, review the safety working system previously as far if reasonable to practise, try to implement the health monitoring, records of assessment and control measures that to be maintained, do training for the drivers and implement the control measures of working system. At least, every two years must do the assessment in order to control on regular basic of vibration exposure onto drivers [9].

Fig. 4 shows the daily VDV exposure level due to type of buses. None of the buses were exceed the ELV. The HINO RK1JSKA, HINO AK1JRKA, and NISSAN JPS251S $\left(11.1 \mathrm{~m} / \mathrm{s}^{1.75}, 9.95\right.$ $\mathrm{m} / \mathrm{s}^{1.75}, 12.65 \mathrm{~m} / \mathrm{s}^{1.75}$ ) exceed the EAV. Others bus was below the EAV. Even though the buses were in condition of safe to operate but if there is any reason which is any circumstances changed significantly happen, the further assessment must be done. One of the factors contributed to the vibration exposure was mostly the buses were experiences more that 13 years on road. 


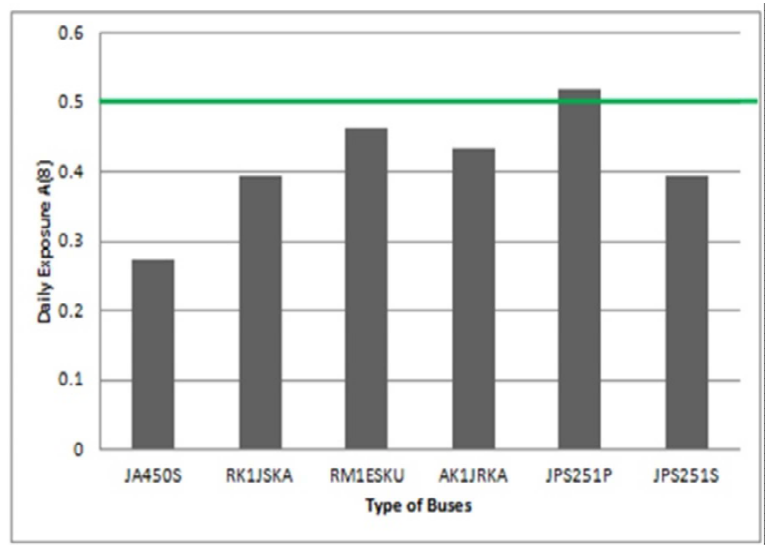

Figure 3: Daily exposure $A(8)$ according to type of buses

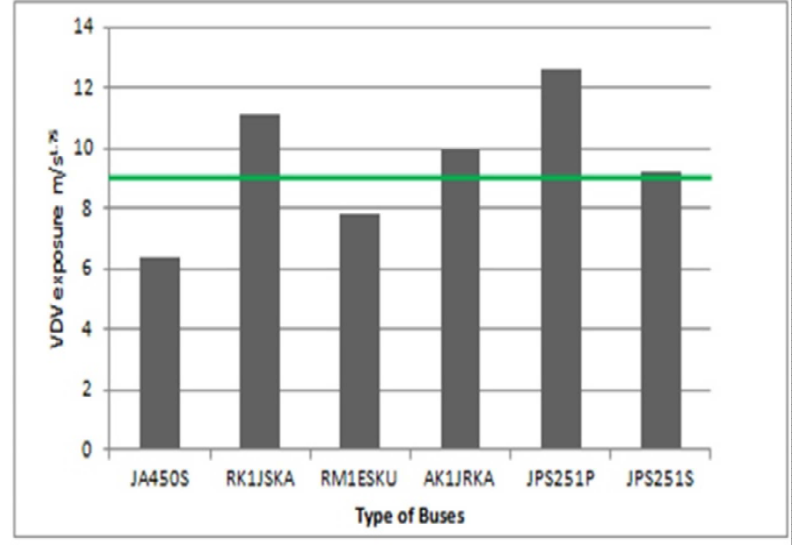

Figure 4: Daily exposure VDV exposure according to type of buses

According to Fig. 3 and Fig. 4, the highest vibration transmitted from the A(8) and VDV was $z$ axis. The value for both were produced by NISSAN JPS251P was equal to $0.52 \mathrm{~m} / \mathrm{s}^{2}$ and 12.65 $\mathrm{m} / \mathrm{s}^{1.75}$. The range of vibration exposure A(8) and VDV by $x, y$ and $z$ was $\left(0.275 \mathrm{~m} / \mathrm{s}^{2}<x \leq 0.415\right.$ $\left.\mathrm{m} / \mathrm{s}^{2}\right),\left(0.200 \mathrm{~m} / \mathrm{s}^{2}<y \leq 0.420 \mathrm{~m} / \mathrm{s}^{2}\right),\left(0.250 \mathrm{~m} / \mathrm{s}^{2}<z \leq 0.520 \mathrm{~m} / \mathrm{s}^{2}\right)$ and $\left(5.30 \mathrm{~m} / \mathrm{s}^{1.75}<x \leq 9.95 \mathrm{~m} / \mathrm{s}^{1.75}\right)$, $\left(5.30 \mathrm{~m} / \mathrm{s}^{1.75}<y \leq 9.95 \mathrm{~m} / \mathrm{s}^{1.75}\right),\left(5.30 \mathrm{~m} / \mathrm{s}^{1.75}<z \leq 9.95 \mathrm{~m} / \mathrm{s}^{1.75}\right)$. That proved, the $z$ direction of vibration high-intensity WBV elevated risk of health impairment due to long exposure and mainly the lumbar spine and the connected nervous be affected [3].

Table 2 shows the data from the statistical analysis. The correlation testing identified that duration to complete single trip, duration for rest, and total bus trip contributed highest correlation toward LBP. Increased duration and increased vibration intensity mean increased vibration dose and are assumed to increase the risk, while periods of rest can reduce the risk [2].That statement was supported by significant level $\alpha<0.500$. Exposed to prolonged bodily vibration on bumpy roads, and waiting for extended periods of time was most frequent health complaint by drivers [10].According to Fig. 3 and Fig. 4, the daily exposure level of A(8) and VDV was under ELV were parallel to the statistical analysis which is the prevalence on LBP was in moderate strength will $\alpha=0.500$ of correlation.

Table 2: Correlation of variables to LBP

\begin{tabular}{|c|c|c|c|c|c|}
\hline Variable factors & $\begin{array}{c}p \text {-value } \\
(\mathrm{n}=36)\end{array}$ & $\begin{array}{c}\alpha \text {-value } \\
(n=36)\end{array}$ & Variable factors & $\begin{array}{c}p \text {-value } \\
(\mathrm{n}=36)\end{array}$ & $\begin{array}{c}\alpha \text {-value } \\
(n=36)\end{array}$ \\
\hline Duration to complete & 0.002 & 0.500 & Type of buses** & 0.166 & 0.236 \\
\hline single trip per minutes* & & & ** Adjustability bus seat & 0.034 & -0.355 \\
\hline * weight & 0.022 & -0.380 & ** Adjustability bus steering & 0.181 & 0.228 \\
\hline * Driving a week per hour & 0.000 & 0.895 & $* *$ seat comfort during & 0.002 & -0.505 \\
\hline * Driving a day per hours & 0.002 & 0.509 & driving & & \\
\hline medical check up & 0.075 & 0.301 & Total bus trip per day & 0.011 & 0.418 \\
\hline height & 0.013 & -0.411 & Duration for rest per minutes & 0.010 & -0.425 \\
\hline
\end{tabular}

*.** shown correlation between each variable

\section{Conclusion}

The study was related to whole-body vibration (WBV) among the UTHM bus driver with standard of ISO 2631-1 (1997) guidelines of two main parameter A(8) and VDV. The correlation between WBV toward LBP was analyzed used BLAZE and SPSS software. The analysis by SPSS would support the BLAZE analysis to validities the result obtained. The result obtained shows that there was moderate prevalence of LBP, but effort should be made in order to minimize the exposure of WBV. Thus, future studies are needed in order to provide more clear evidence which is more 
significant under real working conditions. Results obtained from the study found that the drives no exceed the ELV. The condition considered as safe, but continuous surveillance although the lowfrequency vibration can cause the motion sickness. Thus, following ways could be used to minimize the exposure;

1. If employee's assessment shows significant of health problem, the employer should do the health monitoring from vibration exposure.

2. The employer must provide training, information or attending courses of safety and health

3. Do job rotation to minimize the exposure and install the vibration dampers on equipment.

\section{Acknowledgement}

This study was involved collaboration of Universiti Tun Hussein Onn Malaysia (UTHM) and National Institute of Occupational Safety and Health (NIOSH). We are also grateful and thankful for those who involved direct or indirectly during the process of study.

\section{References}

[1] Okunribido, O. O., Shimbles, S. J., Magnusson, M., \& Pope, M., City bus driving and low back pain: A study of the exposures to posture demands, manual materials handling and whole-body vibration, Applied Ergonomics 38(1) (2007) 29-38.

[2] ISO 2631-1,Mechanical vibration and shock-Evaluation of human exposure to whole-body vibration-Part 1: General requirements (1997).

[3] R.Lundstram \& P.Holmlund, Absorption of energy during whole-body vibration exposure, Journal of Sound and Vibration 215(4) (2008) 789-799.

[4] S.B.M.Tamrin, K.Yokoyama, J.Jalaludin, N.A.Aziz, N.Jemoin, R.Nordin, A.L.Naing, Y.Abdullah, M.Abdullah., The Association between Risk Factors and Low Back Pain among Commercial Vehicle Drivers in Peninsular Malaysia: A Preliminary Result, Industrial Health 45 (2007) $268-278$.

[5] A.W. Salmoni, A.P. Cann, E.K. Gillin, T.R. Eger., Case studies in whole-body vibration assessment in the transportation industry-Challenges in the field, International Journal of Industrial Ergonomic 38(2008) 783-791.

[6] R.P.Blood, J.D.Ploger, M.G.Yost, R.P.Ching, R.P.W. Johnson, P., Whole body vibration exposures in metropolitan bus drivers: A comparison of three seats, Journal of Sound and Vibration 329(1) (2010), 109-120.

[7] Paschold, H. W., \& Sergeev, A. V., Whole-body vibration knowledge survey of U.S. occupational safety and health professionals, Journal of Safety Research 40(3) (2009) 171-176.

[8] I.Kuorinka, B.Jonsson, A.Kilbom, H.Vinterberg, F.Biering-Sorensen, G.Anderson and K.Jorgensen, Standard Nordic questionnaires for the analysis of musculoskeletal symptoms, Applied Ergonomics 18(3) (1987) 233-237.

[9] Occupational Health and Safety. Whole- Body Vibration Procedure, West Lothian Council (2009) 1-29.

[10] J.M.Kirkorowicz, P.Sapukotana, Silva, P., Noda, M., Oliveira, J., \& T.Ostbye, Work-Related Stress and Substance Use as Risk Factors for Chronic Disease Among Three-Wheel Drivers in Gelle,Sri Lanka : A Qualitative Study, Int. J. Occupational Health and Safety 3(2) (2013) 21-23. 